\title{
ORIGINAL CONTRIBUTION Study of Virtual Reality and IoT for Exploring the Deep Sea
}

\author{
Yuan-Hsun Liao ${ }^{1 *}$, Hsiao-Hui Li ${ }^{2}$, Zong-Han Xie ${ }^{3}$ \\ ${ }^{1}$ Research Center for Information Technology Innovation, Academia Sinica, Taipei, Taiwan \\ ${ }^{2,3}$ Department of Information Management, Tainan University of Technology, Tainan, Taiwan
}

\begin{abstract}
In the deep sea, many puzzles have not been solved. We must overcome many difficulties if we want to explore the deep sea. Unpredictable dangers may occur when humans carry out deep-sea exploration. At this time, we can take advantage of Virtual Reality (VR) and the Internet of Things (IoT) characteristics. This paper studies the combination of the IoT and VR that can connect items to the internet, control items and send back data to observe the condition of the equipment and water pressure and break through the space constraints to let people explore the deep sea even in the virtual world. This design will greatly reduce the probability of danger. And the user can achieve the purpose of deep-sea exploration. The ocean is an area that humans have not yet fully developed, and it is also full of mystery and danger. But using VR, you can avoid temperature differences, water pressure and dangerous creatures in the sea. Through VR, you can add new things so that things that can't usually happen in real life can be presented in a virtual way.
\end{abstract}

Index Terms - VR, IoT, Exploring the Deep Sea

Received: 16 April 2019; Accepted: 13 May 2019; Published: 26 June 2019

\section{INTRODUCTION}

With the rapid development of information technology, it has subverted the operating modes of many traditional industries. People have changed many ways of working through the Internet. In recent years, VR has risen rapidly, showing its characteristics and applications in different fields such as education, military, and medical [1, 2]. However, VR is still mostly used for entertainment. Although VR is not widely used in environmental education [3], has great potential in environmental education applications. It is possible to break through environmental constraints and allow learners to simulate the experience and exercise process to help improve understanding and integration.

VR and the IoT are two technologies that are very important in recent years. In VR and the IoT, we understand the possibility of the future by combining the two technologies $[4,5,6]$. Those can make the impossible possible. At present, few researchers apply VR to this field. So, this respect will study.

The ocean accounts for $70 \%$ of the Earth, but the human understanding of the ocean is only $5 \%$, and $95 \%$ of the ocean still a mystery to us. At present, humans can explore about 10000 meters deep in the sea through equipment such as AUV and ROV [7, 8].

Although can explore 10000 meters, people have the means to put themselves in the deep sea 10000 meters of place to feel the deep sea. According to the technology, it's okay; (With the technology of the present it can definitely) Titanic and Avatar's director, James Cameron, did it on a deep-sea challenger in 2012 [9]. It can be done, but the risks are too high. After all, I don't know what kind of danger is in the deep sea. A deep-sea diving robot has combined AUV and ROV in 2015. It burst about 10000

\footnotetext{
${ }^{*}$ Corresponding author: Yuan-Hsun Liao

${ }^{\dagger}$ Email: yuanhsunliao@gmail.com
}

meters deep in the ocean because it couldn't withstand the water pressure at the time. If this were to happen on someone's submarine, it wouldn't be good. Others have been attacked by unknown creatures and things like that.

So, most of the way is looking at the bottom of the ocean through the screen on the boat. But it would be sad if you could only look at the deep ocean through the screen all the time. So, if we can do this with VR, can we look at the deep sea as if we were in the deep sea? That's why this paper comes up with this idea.

This study combines the characteristics of VR through the deepsea environment. The deep-sea image signal is transmitted to the remote VR environment through video equipment. VR is to simulate a real threedimensional scene through real-time computing with a computer combined with 3D graphics and video projection. Users can wear various input and output equipment to interact with objects in the virtual environment. In addition, VR has high interactivity and high immersion. So, users have an immersive feeling when using it. VR has the characteristics of immersive design. The deep-sea exploration of VR has the characteristics of being unaffected by time and space and the seabed environment and capable of self-adjusting video presentation. This paper combines VR with the deepsea environment, and users can be free from time and the external environment when using it. It improves users' vulnerability to time and space due to adverse environmental factors. Users can repeat the operation to enjoy the deep-sea exploration fully. 


\section{IoT IN THE DEEP SEA}

In the environment of rapid development of global communications technology and the popularity of the network infrastructure, such as Wi-Fi, 3G, 4G and 5G etc., human beings have been able to detect, identify and control various devices and objects through the real-time capture of information devices and ubiquitous communication capabilities linking physical objects and big data $[10,11]$. The concept of the IoT was first reported in the article of Scientific American. In everyday life, every object or device has a digital identity to be connected to the Internet [12].

In the era of networking, the interaction between people and people can be connected through the Internet. People can also obtain and search any information and resource on the Internet. Even the communication between objects and objects can be interoperable. This Machine to Machine (M2M) of object network is to connect all objects or machines to each other to exchange information and let them make the right decisions or operations. In other words, the IoT era represents the evolution of computing and communication in information technology. That will require technological innovations in a variety of fields to drive the development, such as small wireless networks, nanotechnology, wireless networks of urban, etc. [13]. IoT can connect any object to the Internet through information-sensing devices, such as Radio Frequency Identification (RFID), infrared sensors, global positioning systems, etc., in accordance with agreed protocols (such as the EPC global standard) for information exchange and communication. That can achieve the objects network for intelligently identifying, locating, tracking, monitoring, and managing objects.

The perception of the IoT is part of the infrastructure. It is mainly responsible for the collection and retrieval of front-end data. Whether objects are camera, microphone, voltage, current, temperature and other environmental sensors, or combined with energy harvesting and power management of piezoelectric switches, thermoelectric generators, thermopile and other environmental sensors. Only by using these sensing components to construct IoT can the real-time operations of the collection, retrieval, calculation, analysis and data intelligence of big data take place. After receiving a large amount of data from the host in the cloud, it will analyze and immediately react to the relevant device. The applications have included logistics, transportation, security, energy, healthcare, construction, manufacturing, home, retail and agriculture [14, 15].

Researchers at Buffalo University have experimented with underwater Wi-Fi [16]. But the way doesn't use radio waves because when radio waves enter the water, the signal attenuation is very fast. So, the way has been used by putting two sensors in the water. The two sensors have passed the data back to the ship's devices that can connect to the wireless network with sound waves.

Using this experiment, think about putting a sensor every few meters in the sea. That allows sound waves to relay data to a ship that can connect to a wireless network.

\section{EFFECT OF PRESSURE ON THE MACHINE}

The submarine's way of resisting pressure is to resist pressure by a hard-outer casing, such as titanium alloys [17]. So, if the shell of the sensor is also made of titanium alloy, there may be a way to place the sensor in the deep sea without being damaged by water pressure.

\section{IMMERSION OF VR}

VR is a computer simulation technology that creates a virtual three-dimensional interaction. By viewing and manipulating the content in the virtual environment, the user can become a participant in the vir- tual space, enabling him to enter a fully realistic virtual world as if he were immersive [18]. And, VR is an image generated by computer simulation, allowing users to imagine that they are in this virtual space. In this way, there is a way to further interact with the simulation environment. In addition to VR, there are two other related fields, i.e., augmented reality and mixed reality. The explanations about augmented reality and mixed reality are as follows:

\section{A. Augmented Reality (AR)}

Compared VR with augmented reality. VR is to virtualize into reality. Augmented reality is to realize reality as virtual. It is not to replace the real space, but to add a virtual object in the real space [19]. Through the combination of camera identification technology and computer programs, the set picture appears in the lens, and the corresponding virtual object appears. For example, Pokemon GO is a game made using AR technology [20].

\section{B. Mixed Reality (MR)}

Neither reality nor virtual. Combine the real world with the virtual world to create a space between virtual and reality. This space creates a new environment and conforms to the visual perception of virtual images. Among them, objects in the real world can coexist with objects in the virtual world and interact instantly. Microsoft's Project-Xray uses this technology [21].

Since VR is not like AR, you must use a map or camera to turn it on. It can't be both real and virtual at the same time as MR. VR is freer and reusable in space than the AR and MR. VR can go anywhere as long as there are modules, such as haunted houses, volcanoes, even the sea or outer space. So, if you want to apply the VR, then teaching is a more appropriate choice.

In the real world, the human sensory system interacts directly with the real thing. In the virtual environment, it also utilizes the human sensory system to interact with virtual things $[22,23,24]$.

- Immersion of visual: Use a Head-Mounted Display to put the picture in front of the eyes. Simulate what the eye sees and isolate the influence of the outside real world on the vision to achieve visual immersion.

- Immersion of auditory: The sound is heard through the headset simulation to hear the sound between the void and isolate the influence of the external sound.

- Immersion of touch: Wear haptic feedback gloves and clothing to simulate the feeling of touching an object through Electrical Muscle stimulation.

\section{SYSTEM DESIGN}

The ocean itself is full of mystery and danger. With the passage of time and the over-exploitation of human beings, the marine ecological environment has been destroyed. In addition to letting people experience the marine environment, exploring the ecology, exploring the depths that ordinary people cannot reach, and promoting the importance of the earth's resources are possible.

Use VR to solve problems that users cannot reach deep seabed sites and solve deep sea activities, water pressure and danger. So, we use the technology of "3D modelling" to create "3D object" scenes, creatures, and equipment. Write interactive programs in a virtual environment to make virtual environment interactions, biological movements, biological sounds, and equipment functions to be vividly designed. Conceptual design is as shown below. 


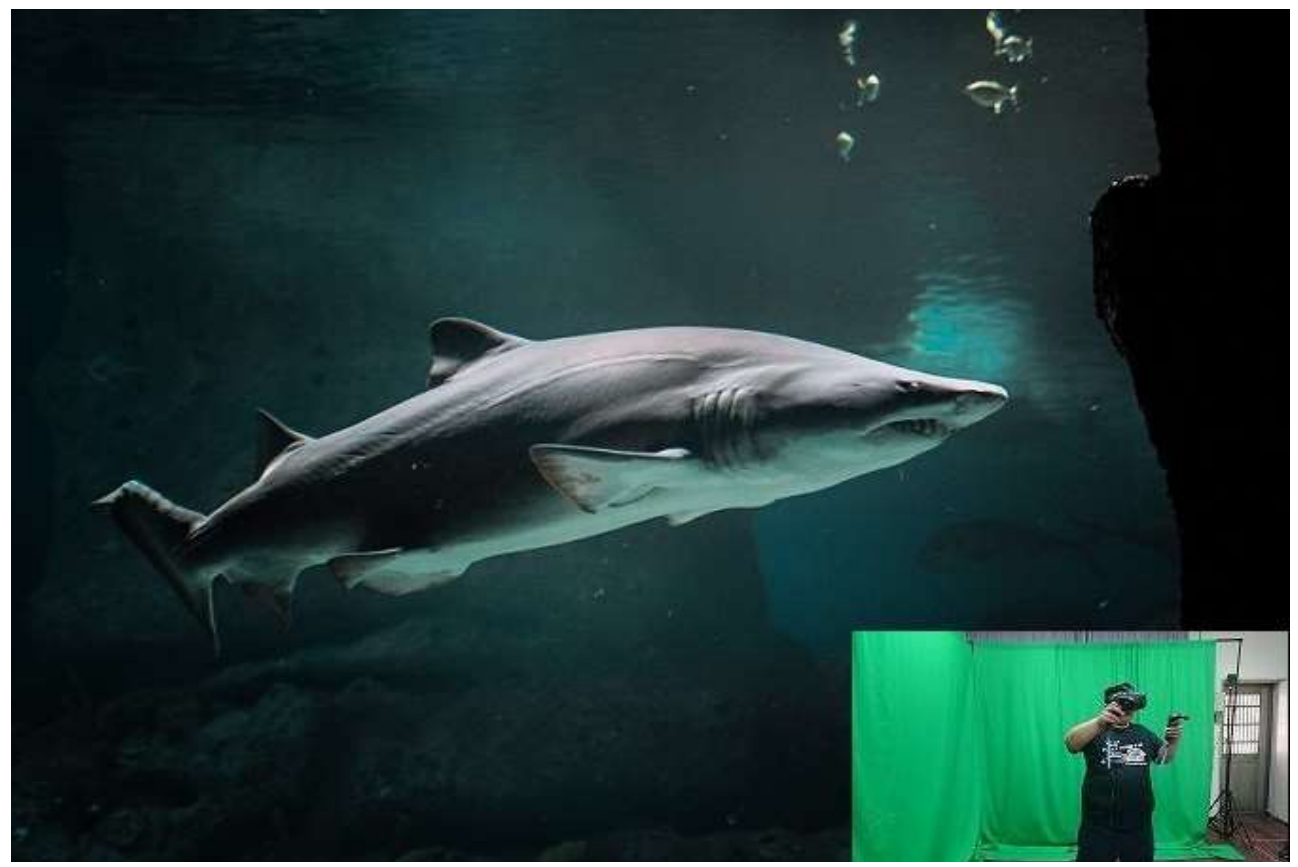

Fig. 1. Conceptual design

Users can interact with deep-sea creatures in the VR world. Through VR simulation, in addition to letting people experience the mysterious ecology of the ocean and the fun of marine life. And, people understand the danger of "sea".

This study uses VR and deep-sea environment to achieve VR implementation. It can be combined with VR through marine ecological video signals. First, we must discuss with the marine biology experts and evaluate the feasibility of the method and the way the signal is presented. After the confirmation is completed, the equipment used in the research, such as the equipment used for exploration and marine environmental information, etc., will be prepared. Data and equipment are ready for development. The development device is a software tool UNITY that supports HTC VIVE. After creating scenes and objects in UNITY, we will start to write scripts. And, the data will continue to collect information during the production process. We will modify and adjust the content of VR's environment by the marine signal data and user experience data and error reports. It interacts with users by incorporating underwater video into the scene. Users deepen the memory and cognition of ocean knowledge through interaction with objects in the virtual world.

\section{RESEARCH LIMITATIONS AND FUTURE RESEARCH DIRECTION}

The current and future implementation of this study has the following limitations:

\section{A. Network Environment}

In the current network environment and equipment, such as satellite signals, $\mathrm{Wi}-\mathrm{Fi}, 3 \mathrm{G}, 4 \mathrm{G}, 5 \mathrm{G}$ etc., there are certain restrictions on the transmission under the sea level, and it is impossible to actually reach the deep sea for wireless signal transmission. Therefore, this study is currently being practised in general lakes. In the future, we hope that wireless transmission will progress to the deep sea and can be effectively transmitted to achieve the best implementation.

\section{B. Data Transmission}

The design of this study is to transmit video signals to the VR environment for real-time. However, the IoT devices currently used are lightweight devices that can be moved and operated in the seabed. Therefore, a small video chip is used on the video device. Because the data transmission efficiency is relatively poor, there will be a delay. In signal processing, the best results are not currently achieved.

\section{Deep-sea Exploration Equipment of IoT}

The current implementation phase of this study is related to IoT equipment which can be used in lakes. But in the future, when it comes to deep-sea implementation, it is necessary to replace it with large equipment. Exploring equipment can effectively resist the environmental impact of Shenzhen and overseas, such as seabed pressure and fish attacks.

\section{CONCLUSION AND IMPLICATIONS}

In today's technology, many problems can be solved, such as the problem of overcoming water pressure and the transfer of data back to the ship in the sea. But, the most important topic of this issue is the study of VR and IoT for Exploring the Deep Sea. At the end of the day, it's just an idea. After all, because of our technical and financial problems, we have not got means to do practical experiments and operations.

The water world is a place where human beings face difficulty in moving or surviving! This paper is to let people explore the unknown ecosystem of the ocean in an experienced way. The ocean is an area that humans have not yet fully developed, and it is also full of mystery and danger. But using VR, you can avoid temperature differences, water pressure and dangerous creatures in the sea. Through VR, you can add new things, so that things that can't usually happen in real life can be presented in a virtual way. 


\section{Declaration of Competing Interest}

The authors declare that there is no conflict of interest.

\section{References}

[1] D. T. Kluger, J. S. Joyner, S. M. Wendelken, T. S. Davis, J. A. George, D. M. Page, D. T. Hutchinson, H. L. Benz, and G. A. Clark, "Virtual reality provides an effective platform for functional evaluations of closed-loop neuromyoelectric control," Transactions on Neural Systems and Rehabilitation Engineering, vol. 27, no. 5, pp. 876-886, 2019. doi: https://doi.org/10.1109/tnsre.2019.2908817

[2] H. Zhao, A. R. Swanson, A. S. Weitlauf, Z. E. Warren, and N. Sarkar, "Hand-in-hand: A communication-enhancement collaborative virtual reality system for promoting social interaction in children with autism spectrum disorders," Transactions on Human-Machine Systems, vol. 48, no. 2, pp. 136-148, 2018. doi: https://doi.org/10.1109/ thms.2018.2791562

[3] P. M. Bosch-Sijtsema and A. Sivunen, "Professional virtual worlds supporting computer-mediated communication, collaboration, and learning in geographically distributed contexts," Transactions on Professional Communication, vol. 56, no. 2, pp.160-175, 2013. doi: https: //doi.org/10.1109/tpc.2012.2237256

[4] A. Somrak, I. Humar, M. S. Hossain, M. F. Alhamid, M. A. Hossain, and J. Guna, "Estimating VR sickness and user experience using different HMD technologies: An evaluation study," Future Generation Computer Systems, vol. 94, pp. 302-316, 2019. doi: https://doi.org/110. 1016/j.future.2018.11.041

[5] M. F. Alam, S. Katsikas, O. Beltramello, and S. Hadjiefthymiades, "Augmented and virtual reality based monitoring and safety system: A prototype IoT platform," Journal of Network and Computer Applications, vol.89, pp. 109-119, 2017.doi: https://doi.org/10.1016/j.jnca. 2017.03.022

[6] A. Meloni, P. Pegoraro, L. Atzori, A. Benigni, and S. Sulis, “Cloudbased IoT solution for state estimation in smart grids: Exploiting virtualization and edge-intelligence technologies," Computer Networks, vol. 130, pp. 156-165, 2018. doi: https://doi.org/10.1016/j.comnet. 2017.10.008

[7] J. Teague, M. J. Allen, and T. B. Scott, "'The potential of low-cost ROV for use in deep-sea mineral, ore prospecting and monitoring," Ocean Engineering, vol. 147, pp. 333-339, 2018. doi: https://doi.org/10. 1016/j.oceaneng.2017.10.046

[8] P. I. Macreadie, D. L. McLean, P. G. Thomson, J. C. Partridge, D. 0. Jones, A. R. Gates, M. C. Benfield, S. P. Collin, D. J. Booth, L. L. Smith, E. Techera, D. Skropeta, T. Horton, C. Pattiaratchi, T. Bond, and A. M. Fowler, "Eyes in the sea: Unlocking the mysteries of the ocean using industrial, Remotely Operated Vehicles (ROVs)," Science of The Total Environment, vol. 634, pp. 1077-1091, sep 2018. doi: https: //doi.org/10.1016/j.scitotenv.2018.04.049

[9] B. Hammond, "The shoreline in the sea: liminal spaces in the films of James Cameron," Continuum, vol. 27, no. 5, pp. 690-703, 2013. doi: https://doi.org/10.1080/10304312.2013.824864

[10] C. Ge, N. Wang, I. Selinis, J. Cahill, M. Kavanagh, K. Liolis, C. Politis, J. Nunes, B. Evans, Y. Rahulan, N. Nouvel, M. Boutin, J. Desmauts, F. Arnal, S. Watts, and G. Poziopoulou, "QoE-assured live streaming via satellite backhaul in 5G networks," Transactions on Broadcasting, vol. 65, no. 2, pp. 381-391, 2019. doi: https://doi.org/10.1109/tbc. 2019.2901397
[11] N. J. Venkatesan, C. S. Nam, E. Kim, and D. R. Shin, "Analysis of realtime data with spark streaming," Journal of Advances in Technology and Engineering Research, vol. 3, no. 4, pp. 108-116, 2017. doi: https: //doi.org/10.20474/jater-3.4.1

[12] N. Gershenfeld, R. Krikorian, and D. Cohen, "The internet of things," Scientific American, vol. 291, no. 4, pp. 76-81, 2004. doi: https://doi. org/10.1038/scientificamerican1004-76

[13] G. Kortuem, F. Kawsar, V. Sundramoorthy, and D. Fitton, "Smart objects as building blocks for the internet of things," IEEE Internet Computing, vol. 14, no. 1, pp. 44-51, 2010. doi: https://doi.org/10.1109/ mic.2009.143

[14] M. Min, X. Wan, L. Xiao, Y. Chen, M. Xia, D. Wu, and H. Dai, “Learningbased privacy-aware offloading for healthcare IoT with energy harvesting," IEEE Internet of Things Journal, vol. 6, no. 3, pp. 4307-4316, 2019. doi: https://doi.org/10.1109/jiot.2018.2875926

[15] N. Neshenko, E. Bou-Harb, J. Crichigno, G. Kaddoum, and N. Ghani, "Demystifying IoT security: An exhaustive survey on IoT vulnerabilities and a first empirical look on internet-scale IoT exploitations," Communications Surveys \& Tutorials, vol. 21, no. 3, pp. 2702-2733, 2019. doi: https://doi.org/10.1109/comst.2019.2910750

[16] J. Edwards, "Signal processing plays a key role in wireless research: New technologies promise to boost speed, bandwidth, availability, and reliability," Signal Processing Magazine, vol. 33, no. 4, pp. 10-13, 2016.

[17] J. R. MacKay and F. van Keulen, "Partial safety factor approach to the design of submarine pressure hulls using nonlinear finite element analysis," Finite Elements in Analysis and Design, vol. 65, pp. 1-16, 2013. doi: https://doi.org/10.1016/j.finel.2012.10.009

[18] M. Kandaurova and S. H. M. Lee, “The effects of virtual reality (VR) on charitable giving: The role of empathy, guilt, responsibility, and social exclusion," Journal of Business Research, vol. 100, pp. 571-580, 2019. doi: https://doi.org/10.1016/j.jbusres.2018.10.027

[19] N. N. M. Nizar, M. K. Rahmat, S. Z. Maaruf, and S. M. Damiodoi, "Understanding augmented reality technology continuance intention through MARLCardio: A perspective of Malaysian higher institutions students," International Journal of Technology and Engineering Studies, vol. 5, no. 1, pp. 9-15, 2019. doi: https://dx.doi.org/10. 20469/ijtes.5.10002-1

[20] R. Shea, D. Fu, A. Sun, C. Cai, X. Ma, X. Fan, W. Gong, and J. Liu, "Location-based augmented reality with pervasive smartphone sensors: Inside and beyond pokemon go!" IEEE Access, vol. 5, pp. 96199631, 2017. doi: https://doi.org/10.1109/access.2017.2696953

[21] C. Chinara, G. Feingold, A. Shanbhag, and K. Weiniger, "ARnold: A mixed reality short film using microsoft HoloLens," SMPTE Motion Imaging Journal, vol. 127, no. 10, pp. 39-45, 2018. doi: https://doi. org/10.5594/jmi.2018.2868437

[22] F. Škola and F. Liarokapis, “Embodied VR environment facilitates motor imagery brain-computer-interface training," Computers \& Graphics, vol. 75, pp. 59-71, 2018. doi: https://doi.org/10.1016/j.cag. 2018.05.024

[23] H. Song, Q. Peng, J. Zhang, and P. Gu, “A VR-based interactive system to improve users' involvement in OAP development," Procedia CIRP, vol. 56, pp. 13-18, 2016. doi: https://doi.org/10.1016/j.procir.2016. 10.008

[24] T.-K. Huang, C.-H. Yang, Y.-H. Hsieh, J.-C. Wang, and C.-C. Hung, “Augmented Reality (AR) and Virtual Reality (VR) applied in dentistry," The Kaohsiung Journal of Medical Sciences, vol. 34, no. 4, pp. 243-248, 2018. doi: https://doi.org/10.1016/j.kjms.2018.01.009 